\title{
DISTRIBUTION OF TENSION WOOD AND ITS RELATION TO LONGITUDINAL SHRINKAGE IN ASPEN
}

February 1952

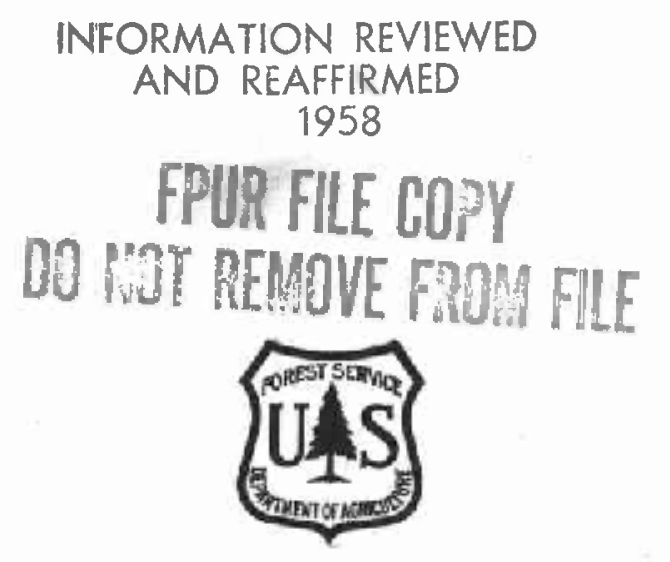

No. R1917

UNITED STATES DEPARTMENT OF AGRICULTURE FOR S T SER VICE

FOREST PRODUCTS LABORATORY $M$ a dis on 5 , Wisconsin

In Cooperation with the University of Wisconsin 


\title{
LONGITUDINAL SHRINKAGE IN ASPEN
}

\author{
By \\ BESSTE Z. TERRELL, Botanist \\ Forest Products Laboratory, 1 Forest Service \\ U. S. Department of Agriculture
}

\begin{abstract}
Introduction
The distribution of tension wood, an abnormal type of wood characterized by the presence of gelatinous fibers, was determined with respect to the upper, lower, and lateral sides of aspen (Populus tremuloides) logs from lcaning trces. The interrelationship of longitudinal shrinkage to comparative number of gelatinous fibers and specific gravity also was determined, since tension wood has exceptionally large shrinkage along the grain. This work was part of investigations at the Forest Products Laboratory on the occurrence and properties of tension wood, which is partially responsible for such unsatisfactory behavior as warping and poor machining qualities in certain hardwood species.

Akins and Pillow (1) ${ }^{2}$ found that tension wood in white oak has greater longitudinal shrinkage than normal wood and, in mahogany, Pillow (6) found that the longitudinal shrinkage tended to increase directly with the number of gelatinous fibers in the test specimens. Numerous examinations of lumber at the Forest Products Laboratory have shown that warping is caused by the greater shrinkage of tension wood in comparison with that of normal wood in the same pieces, which sets up internal stresses during drying of the wood.

S. H. Clarke (3) reported tension wood in English beech on the upper side of leaning trees. Examination of certain western cottonwood logs at the Forest Products Laboratory, however, indicated that some gelatinous fibers may be distributed on nearly all sides of the logs, not just on the upper side as reported for some species $(I, 3)$. In other observations during the sawing of aspen lumber, the presence of tension wood was indicated by its characteristically projecting fibers on all sides of some logs, without any special
\end{abstract}

I Maintained at Madison, Wis., in cooperation with the University of
Wisconsin.
2 Underlined numbers in parentheses refer to Literature Cited at end of paper.

Rept. No. RI917

$-1-$

Agriculture-Madison 
concentration on the upper side of leaning trees. Hence, there is a need for basic information on the distribution of tension wood and the relation of the number of its gelatinous fibers to longitudinal shrinkage of the wood.

\section{Selection and Preparation of Test Material}

The aspen test specimens were taken from two butt logs that were selected because their appreciable sweep indicated that they originated in leaning trees. From these logs, 1-inch-thick boards were sawed that represented the upper (concave), lower (convex), and lateral surfaces of the trees as they originally stood. When freshly sawed from the logs, these boards generally were bowed with the concave surface toward the bark, because longitudinal stresses were greatest at that surface (fig. 1). Frequently, the boards showing the greatest deformation also were extremely fuzzy, a characteristic that often seems to be associated with the presence of tension wood $(\underline{1}, \underline{6})$.

Samples for determinations of longitudinal shrinkage were cut from the full width and from each end of the boards and thereby represented wood from heights, respectively, of about 1 to 2 feet and 8 to 9 feet above the ground. Each sample was about 12 inches long and planed on both surfaces. One edge of each was jointed before consecutive specimens, about I inch square in cross section, were ripped from the full width of the sample. The ripping was done with a smooth-cutting saw that ordinarily produced exceptionally smooth surfaces. On some surfaces, however, considerable torn grain occurred, apparently because of the presence of tension wood. Both ends of the specimens were trimmed, so that the finished lengths of the specimens were about 9-1/2 inches.

Each test specimen was designated by the following: The letter $L$ or $M$ to distinguish the two logs; the letter $A$ or $B$ to indicate a specimen from the butt or top, respectively; a sample number to indicate the side of the log with respect to lean of the tree; and a specimen number. The boards from $\log I$ were numbered $1,3,5$, and 7 , and those from $\log M$ were numbered 11 , 13, 15, and 17. A designation for a typical specimen, IA-7-1, would therefore mean $\log L$, butt region, sample 7 (upper side), specimen $I$. Figure 2 shows positions of the test specimens with respect to upper, lower, and lateral sides of the two leaning aspen trees. The 8 boards from the 2 logs produced 77 specimens, on which longitudinal shrinkage, specific gravity, and comparative number of gelatinous fibers were determined.

After the specimens were cut to final size, they were evacuated of air under distilled water by a water suction pump and then soaked about 12 hours at room temperature. This treatment replaced small amounts of moisture in the wood that were lost during storage and processing of the specimens and thereby approximated the green condition of the wood for the first measurements. 
Lengths of the specimens in the green condition were measured to the nearest 0.001 inch with a dial micrometer. The green volume was determined by the buoyancy of the specimens in water in order to calculate their specific gravity. The specimens were air dried to approximate moisture equilibrium successively at $65^{\circ}$ and 30 percent relative humidity at $80^{\circ} \mathrm{F}$., and then were oven dried to constant weight at $105^{\circ} \mathrm{C}$. Both the length and weight of the oven-dry specimens were determined. From these measurements, longitudinal shrinkage was calculated as a percentage of the green length, and specific gravity was calculated on the basis of green volume and oven-dry weight of each specinen.

The comparative numbers of relatinous fibers were determined by microscopical examination of sections from a block of wood, $5 / 3$ inch along the grain, taken from each test specimen. Bach block was split into four approximately ecual pieces, and the pioces were boiled in distilled water and stored in 70 percent alcohol. Complete cross sections, about 13 microns thick, were cut on a slidins microtome from each of the four pieces, and together represented the entire cross section of each test specimen. The microtome sections wcre treated with chloriodicie of zinc (S) and examined microscopically, undor as nearly standard concitions as pośsible.

The estimate for the comparative number of gelatinous fibers in each cross section was based on a numerical value representing their frequency, such as occasional, scattered, ahundant, or solid groupings. The portion of the entire cross-sectional area occupied by these fibers, whether approximately $2 / 3,1 / 2,1 / 3,1 / 4,1 / 5$, or $1 / 12$, represented their distribution. From these values for frequency and distribution of gelatinous fibers, a product was calculated to express the comparative rumber of gelatinous fibers per unit area for each test specimen. This product, of course, is only an estimate of the actual number of gelatinous fibers in the specimen, but is sufficiently accurate for the comparisons needed. Figure 3 is a photomicrom graph showing the frequency that constituted a solid grouping of gelatinous fibers, and figure 4 shows the frequency of a scattered grouping of gelatinous fibers among normal fibers.

\section{Characteristics of Tension Wood in Aspen}

The gelatinous fibers of tension wood in aspen had the typical characteristics of the abnormal fibers described br Akins and Pillow (I); that is the inner layers of their secondary cell walls were identified by specific reactions to certain biological dyes and reagents. The aspen fibers, which have a moderately thick wall, had a fairly thick gelatinous layer. This layer was buckled and pulled away from the rest of the secondary wall, so that it looked like a distinct layer (fig. 3). Because of this separation, the gelatinous layer has been called a tertiary wall by some authors (2).

Celatinous fibers appeared to be normally distributed in all the test specimens (fig. 5). They were found on all sides of both logs, but their comparative numbers varied widely in different specimens. The largest concentrations of gelatinous fibers were on the upper or tension sides at the butt

Rept. No. RI9I7 -3- 
regions of the logs, while considerably fewer of these fibers were found on the lower sides. This area of greatest concentration of these abnormal fibers was also correlated with the greatest longitudinal shrinkage.

At the tops of both logs, the gelatinous fibers were more uniformly distributed on all sides than at the butts. The upper sides, however, showed greater concentrations of gelatinous fibers and greater longitudinal shrinkace than the lower sides. The average number of gelatinous fibers at the tops of the logs was slightly greater than the average number at the butt regions, but the difference was not statistically significant in either log. In a comparison of average values for $\log \mathrm{L}$ and $\log \mathrm{M}$, $\log \mathrm{L}$ had significantly higher values for both comparative number of gelatinous fibers and longitudinal shrinkage than Log $\mathrm{M}$. Table 1 shows values for longitudinal shrinirage, specific sravity, and number of gelatinous fibers for all sides of both loss, as well as top, butt, and log averages.

Values for longitudinal shrinkage in all the test specimens were concentrated in the lower end of the range, although some shrinkage values were appreciably above the average (fig. 6). A considerable number of specimens had higher values than Koehler (5) considered to be the usual range of longitudinal shrinkage, namely, 0.1 to 0.3 percent of the green dimensions. Longitudinal shrinkage was greatest for the upper sides of both logs but fell within the usual range for shrinkage for the lower sides. LoE I had significantly higher values for longitidinal shrinkage than log $\mathrm{i}$ (table 1 ).

\section{Variability of Longitudinal Shrinkage}

Longitudinal shrinkage did not appear to be closely correlated with specific gravity, which had about the same range in both logs (fig. 7). Longitudinal shrinkage was correlated to a moderate extent with the comparative number of gelatinous fibers, but varied widely, expecially with large numbers of gelatinous fibers (fig. 8).

The relations between one variable and two others operating jointly can be shown in a three-dimensional graph (4). For this work, the values for the test specimens were classified by specific gravity and by number of gelatinous fibers. Series of approximations were made alternately of relationships of longitudinal shrinkage to number of gelatinous fibers and to specific gravity. That procedure included successive approximations until there was essentially no change in the estimated relationship of longitudinal shrinlage to either number of gelatinous fibers or specific gravity. These data were combined in a three-dimensional graph that shows trends of longitudinal shrinkage of aspen varring with both number of gelatinous fibers and specific gravity (fis. 9).

The three-dimensional graph shows that longitudinal shrinkage is in direct linear relation to the number of gelatinous fibers in each of the specific gravity classes. When specific gravity is held approximately constant, an increase in number of gelatinous fibers is accompanied by an increase in longitudinal shrinkage. On the other hand, the general relationship of

Rept, No. PI9I7 -4- 
increasing longitudinal shrinkage to increasing specific gravity, within each of the gelatinous-fiber classes, follows a curved pattern. For relatively small numbers of gelatinous fibers, increase in longitudinal shrinkage with increase in specific gravity occurs principally in the upper part of the range of specific gravity (fig. 9). For moderate and larger numbers of gelatinous fibers, shrinkage increases along nearly straight lines in the lower part of the range of specific gravity and more rapidly along curved lines as the specific gravity increases.

The curves showing relationship of shrinkage to specific gravity were generally similar in shape and differed principally in the elevations above the base. These elevations represent longitudinal shrinkage at different combinations of number of gelatinous fibers and specific gravity. The greatest longitudinal shrinkage was found ccordinately with large numbers of gelatinous fibers and large specific gravity (fig. 9). Large specific gravity appeared to be correlated with relatively thick gelatinous layers of tension-wood fibers.

These data show the general combined effects of number of gelatinous fibers and specific gravity on longitudinal shrinkare. Such a small number of specimens, howevcr, does not permit the calculation of a mathematical equation expressing the three-dimensional relationship of these factors.

\section{Conclusions}

Gelatinous fibers, which characterize tension wood, were distributed in varying number on all sides of two aspen logs from leaning trees, The greatest concentration of these fibers was on the upper or tension side of the logs. Determination of the relationship of longitudinal shrinkage to number of gelatinous fibers and specific gravity in test specimens led to the following conclusions:

1. Longitudinal shrinkage is related to the comparative number of gelatinous fibers.

2. Combined factors of numbers of gelatinous fibers and specific gravity jointly affect longitudinal shrinkage of aspen. That is, the percentage of longitudinal shrinkage was greatest in specimens having largest values for specific gravity and largest number of gelatinous fibers with relatively thick cell walls.

3. The determination of combined functions of three variables is a valuable tool for determinine relations between anatomical features and properties of wood.

Rept. No. RI917 
(1) AKINS, VIRGINIA and PILION, M. Y.

1950. OCCURRENCE OF GELATINOUS FIBERS AND THEIR EFFECT UPON PROPERTTES OF HARDICOD SPECIES.

Proc. Forest Products Research Society, Vol. 4.

(2) CLARITS, S, H.

1930. HOHE-GROWN TIVBEERS: THEIR ANATOMICAL STRUCTURE AND ITS RELATION TO PHYSICAL PROPERTIES, EIY.

For. Prod. Res.BuIl. No. 7. Forest Products Research Laboratory, Aylesbury, England.

(3)

1937. THE DISTRISUTION, STRUCTURT, AND FROPERTIES OF TENSION WOOD Iil BEECH (Fagus sylvatica L.).

Forestry Vol. 11, To, ?.

(4) EZEYTEI, MARDECAI

1947. NETHODS OF CORIELATION ANAIYSIS.

New York.

(5) KOEILER, ARTHUR.

1946. LONGITUDINAI. SHRIMKACE OF WOOD.

Forest Products Laboratory Rept. No. RI093.

(6) PILLON, M. Y.

1950. PRESENCE OF TENSION WOOD IN MAHOGANY IN REIAATION TO

LONGITUDINAL SHRINKAGE.

Forest Products Laboratory Rept. No, D1763.

Rept. No. RI917 -6- 
Table 1.--Long1tudinal ohrinkage, speciflc gravity, and comperative numbers of gelatinous fibers for tegt specimens from two espen logs from leaning trees

\begin{tabular}{|c|c|c|c|c|c|c|c|c|c|c|c|c|c|c|c|c|c|c|c|c|c|c|}
\hline \multirow{4}{*}{$\begin{array}{l}\text { Desigmation } \\
\text { of } \\
\text { opecimen }\end{array}$} & \multirow{4}{*}{$\begin{array}{l}: \text { side o } \\
: \quad \log \\
:\end{array}$} & \multirow{4}{*}{$\begin{array}{r}: \\
: \\
: \\
:\end{array}$} & \multirow{4}{*}{$\begin{array}{l}\text { Number } \\
\text { of } \\
\text { spect- } \\
\text { mens }\end{array}$} & \multirow{2}{*}{\multicolumn{3}{|c|}{ : Longitu }} & & & & \multirow[t]{2}{*}{$:$} & & \multirow{2}{*}{\multicolumn{7}{|c|}{ :Comparative number of gelatinous fibers 3}} \\
\hline & & & & & & & 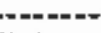 & & m-men & & 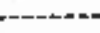 & Speciflc gravity $?$ & 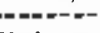 & & - & & & & & & & \\
\hline & & & & $:$ & Average & & Animum & & lar 1 moum & $: A$ & Averege & & intmum & & laximum & : & Average & : & Minfmum & : & Max & ximum \\
\hline & & & & : & & : & & $:$ & & $:$ & & : & & $:$ & & : & & : & & : & & \\
\hline & $:=$ & : & & : & Percent & $:$ & Percent & $:$ & Percent & $\because$ & & : & & : & & $:$ & & : & & : : & & \\
\hline & $:$ & $:$ & & 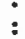 & & : & & : & & : & & $:$ & & : & & : & & : & & : & & \\
\hline Log I & : & : & & : & & $:$ & & $:$ & & : & & : & & $:$ & & : & & : & & : & & \\
\hline & : & : & & : & & : & & : & & $:$ & & : & & : & & : & & : & & : & & \\
\hline I-A-I & : Latera & & 7 & : & 0.260 & $:$ & 0.234 & : & 0.287 & $:$ & 0.382 & : & 0.373 & : & 0.387 & : & 22 & : & 12 & : & & 31 \\
\hline L-A-3 & : . . do.. & & 5 & : & .470 & : & .287 & : & .648 & : & .405 & : & .379 & : & .425 & : & 35 & ; & 22 & : & & 41 \\
\hline L-A-5 & : Lower & : & 4 & : & .218 & : & .212 & : & .234 & : & .378 & : & .373 & : & .382 & : & 14 & ; & 10 & : & & 17 \\
\hline I-A-7 & : Upper & : & 4 & : & .684 & : & .658 & $:$ & .722 & : & .424 & : & .421 & $:$ & .435 & : & 45 & : & 34 & $:$ & & $5 i$ \\
\hline & $:$ & : & & : & & : & & : & & $:$ & & : & & : & .: & : & & $:$ & & : & & \\
\hline Butt & : & $:$ & & : & & $:$ & & $:$ & & $:$ & & : & & : & & $:$ & & : & & : & & \\
\hline average. & $\ldots \ldots$ & $\ldots$ & .20 & : & .389 & : & & $:$ & & : & .396 & : & & : & & : & 29 & : & & : & & \\
\hline & : & : & & : & & $:$ & & : & & : & & : & & : & & : & & : & & $:$ & & \\
\hline $\mathrm{L}-\mathrm{B}-\mathrm{I}$ & : Latera & & 5 & : & .276 & : & .265 & : & .287 & $:$ & .384 & : & .370 & : & .395 & : & 28 & : & 24 & : & & 33 \\
\hline$I-B-3$ & $\therefore$. do... & & 4 & : & .284 & : & .244 & : & .319 & $:$ & .378 & : & .367 & $:$ & .383 & : & 31 & : & 21 & : & & 38 \\
\hline $\mathrm{L}-\mathrm{B}-5$ & : Lower & : & 4 & : & .273 & $:$ & .265 & : & .287 & : & .396 & : & .380 & : & .407 & : & 24 & : & 19 & : & & 28 \\
\hline L-B-7 & : Upper & : & 4 & : & .358 & : & .340 & : & .382 & $:$ & .383 & : & .379 & : & .385 & : & 38 & : & 34 & $:$ & & 44 \\
\hline & : & : & & : & & : & & $:$ & & : & & : & & : & & $:$ & & : & & ; & & \\
\hline Top & : & : & & : & & : & & : & & : & & : & & $:$ & & : & & : & & : & & \\
\hline average. & $\ldots$ & $\cdots$ & .17 & : & .297 & $:$ & & : & & : & .385 & : & & : & & : & 30 & ; & & : & & \\
\hline & : & : & & : & & : & & : & & $:$ & & : & & $:$ & & $:$ & & $:$ & & : & & \\
\hline Log & : & : & & : & & : & & : & & : & & : & & $:$ & & : & & : & & : & & \\
\hline average. & $\ldots+\ldots+\ldots$ & $\cdots$ & .37 & : & .346 & : & & : & & : & .390 & $:$ & & : & & : & 29 & : & & : & & \\
\hline & : & : & & : & & $:$ & & : & & : & & : & & : & & : & & : & & : & & \\
\hline & $:$ & : & & : & & $:$ & & $:$ & & $:$ & & : & & : & & : & & : & & ; & . & \\
\hline $\log M$ & : & : & & : & & : & & $:$ & & : & & : & & : & & $:$ & & : & & : & & \\
\hline & : & : & & : & & : & & : & & : & & : & & : & & : & & : & & : & & \\
\hline M-A-11 & : Latera & & 6 & $:$ & .234 & $:$ & .181 & : & .319 & : & .406 & : & .397 & $:$ & .423 & : & 10 & $:$ & 2 & : & & 17 \\
\hline$M-A-13$ & :...do.. & & 6 & $:$ & .200 & $:$ & .159 & : & .276 & : & .398 & : & .389 & : & .407 & : & 16 & : & 8 & : & & 20 \\
\hline$M-A-15$ & : Lower & : & 4 & : & .244 & : & .212 & : & .319 & $:$ & .413 & : & .389 & : & .433 & : & 2 & : & 1 & : & & 3 \\
\hline$M-A-17$ & : Upper & : & 5 & : & .319 & $:$ & .276 & : & .351 & : & .394 & $:$ & .391 & $:$ & .397 & : & 23 & : & -28 & $:$ & & 39 \\
\hline & : & $:$ & & : & & : & & : & & : & & : & & $:$ & & : & & : & & : & & \\
\hline Butt & : & : & & : & & : & & : & & $:$ & & : & & : & & : & & : & & $:$ & & \\
\hline average. & , & ... & .21 & : & .246 & : & & : & & : & .402 & : & & : & & : & 15 & $:$ & & $:$ & & \\
\hline & : & : & & : & & : & & : & & : & & : & & : & & : & & : & & : & & \\
\hline $\mathrm{M}-\mathrm{B}-\mathbf{L 1}$ & : Latera & & 6 & : & .223 & : & .191 & : & .276 & : & .384 & $:$ & .378 & $:$ & .394 & : & 19 & : & 12 & : & & 30 \\
\hline$M-B-13$ & : ...do... & & 3 & : & .191 & : & .181 & : & .202 & : & .378 & : & .377 & : & .379 & $:$ & 21 & ; & 18 & : & & 22 \\
\hline M-B-15 & : Lower & : & 5 & : & .187 & $:$ & .170 & : & .202 & : & .388 & : & .383 & : & .394 & : & 24 & : & 19 & $:$ & & 30 \\
\hline M-B-17 & : Upper & $:$ & 5 & : & .238 & : & .202 & $:$ & .319 & : & .368 & : & .364 & : & .373 & : & 26 & 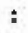 & 20 & : & & 28 \\
\hline & : & : & & : & & $:$ & & : & & : & & : & & : & & : & & : & & ; & & \\
\hline Top & : & : & & : & & : & & $:$ & & : & & : & & $:$ & & : & & ; & & : & & \\
\hline average. & $\ldots$ &.+1 & +19 & : & .212 & : & & : & & : & .380 & : & & : & & : & 22 & : & & : & & . \\
\hline & : & : & & : & & : & & : & & : & & : & & $:$ & & : & & : & & : & & \\
\hline Log & : & : & & : & & : & & : & & : & & $:$ & & : & & : & & : & & : & & \\
\hline average. & $\ldots . .$. & I & +40 & : & .230 & : & & : & & : & .392 & : & & : & & $:$ & 19 & : & & : & & \\
\hline & : & : & & : & & : & & : & & : & & : & & : & & : & & : & & : & & \\
\hline & $:$ & $:$ & & $:$ & & $:$ & & : & & $:$ & & $:$ & & $:$ & & : & & : & & : & & \\
\hline
\end{tabular}

I Besed on green dimension.

$\hat{2}_{\text {Beeed on }}$ green volume and weight when oren dry.

3Calculated from the frequency and dietribution of gelatinous fibere as estimated by microacopical examination.

Rept. No. R1917

Z M 89438 F 
Figure 1.--Bowed boards cut from the outside of an aspen log.

The concave surface is towards the bark,

(ZM83030F)

Rept. No. R1917 


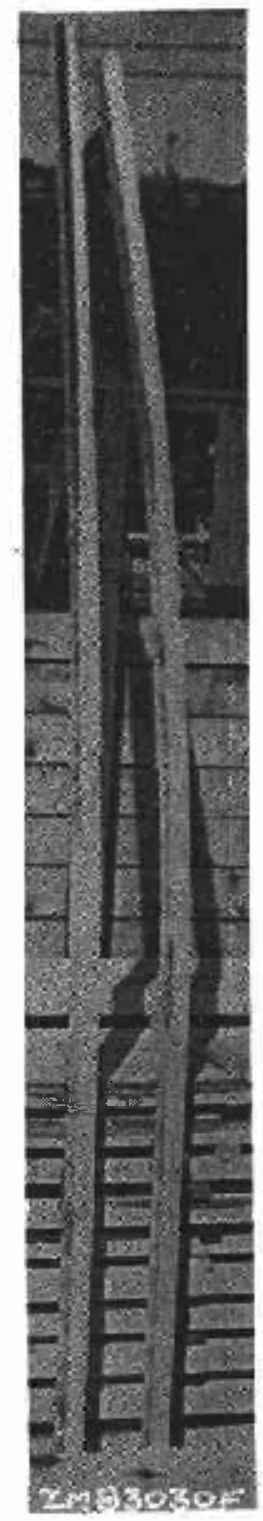


Figure 2.-Diagrams of the cross sections fron the two aspen logs, showing the arrangement of the samples and of the test specimens with relation to the convex and concave sides of the logs.

(2N874 $71 F)$

Rept. No. RI917 


\section{TOP}
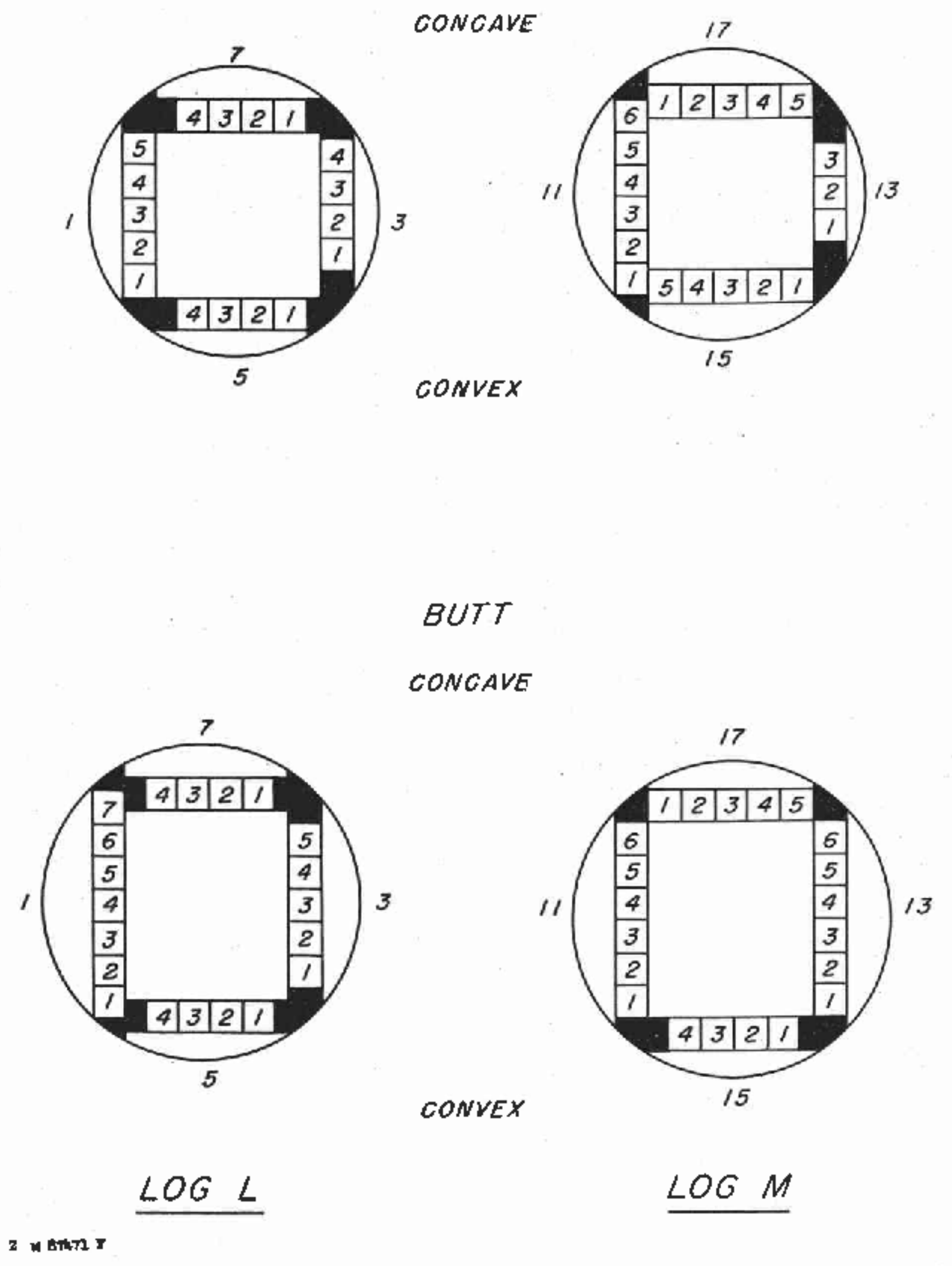
Figure 3.-Photomicrograph of a section offaspen, showing a solid grouping of gelatinous fibers with the buckled Eelatinous layer clearly visible. X/400.

(2N86992F)

Rept. No. R1917 


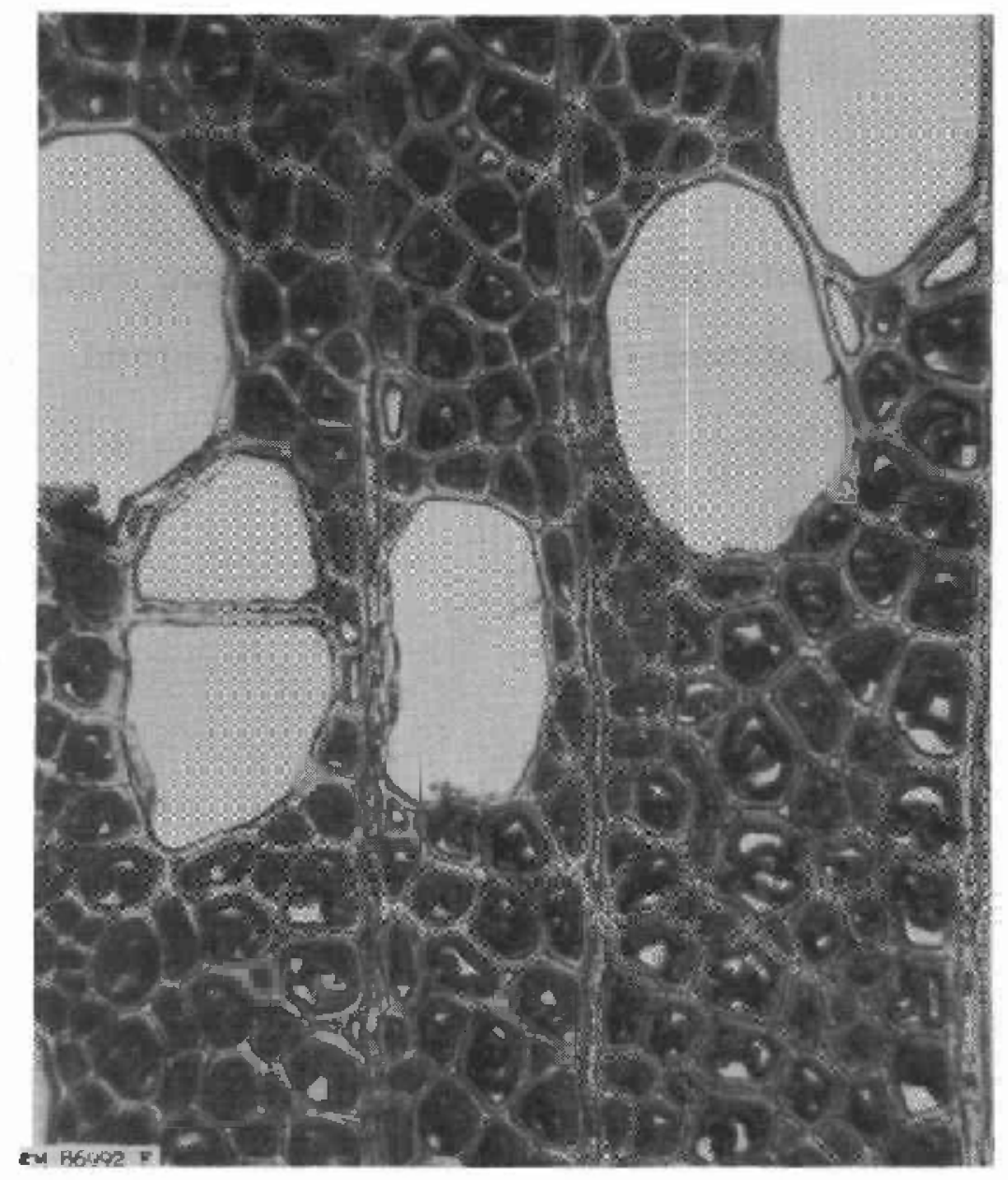


Figure 4.--Photomicrograph of a section of aspen, showing gelatinous fibers scattered among normal fibers. Xl400.

(ZR-86989F) 


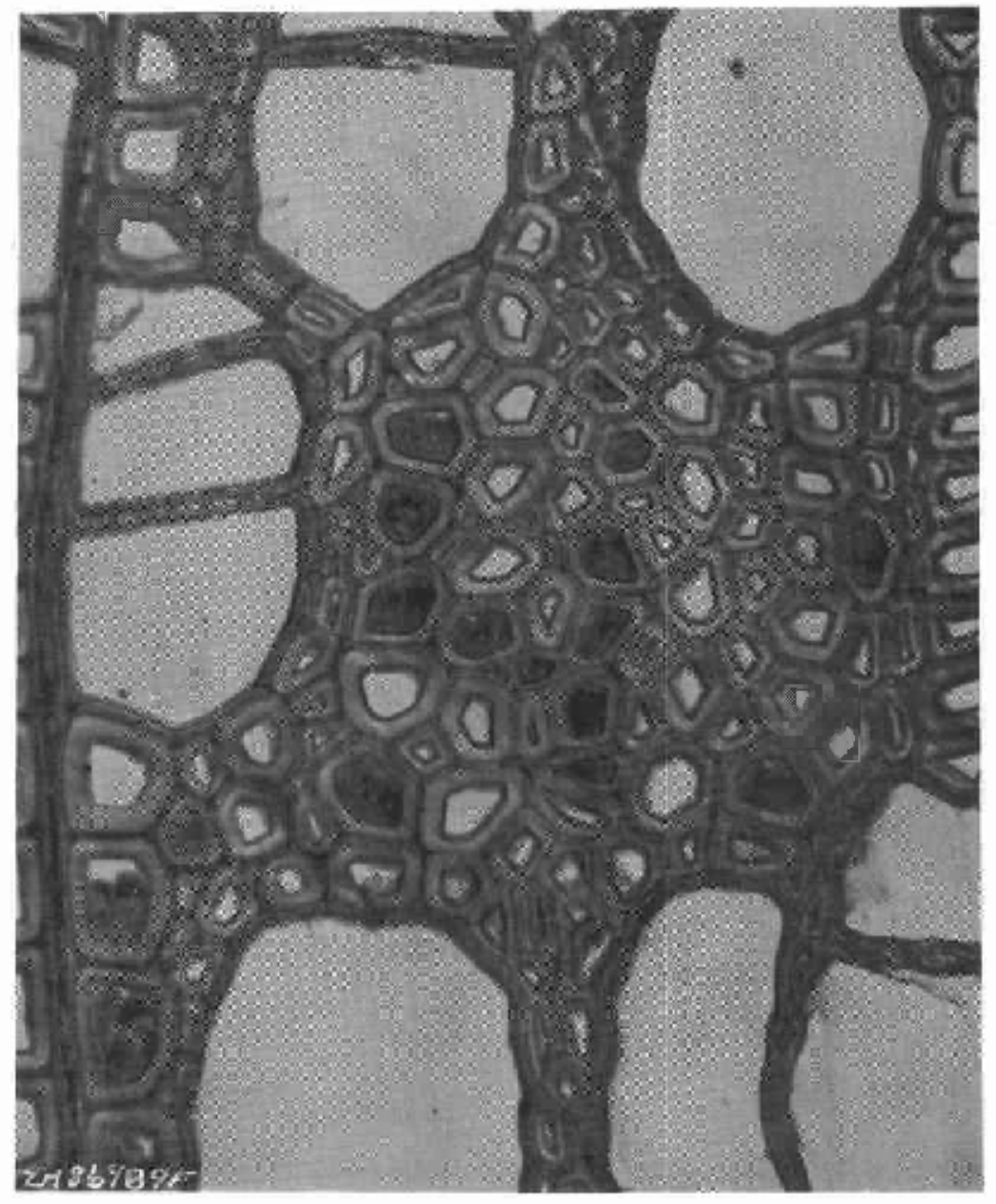


Figure 5.-Frequency distribution of values for comparative number of gelatinous fibers from all the test specimens.

(ZN87467F)

Rept. No. RI917 


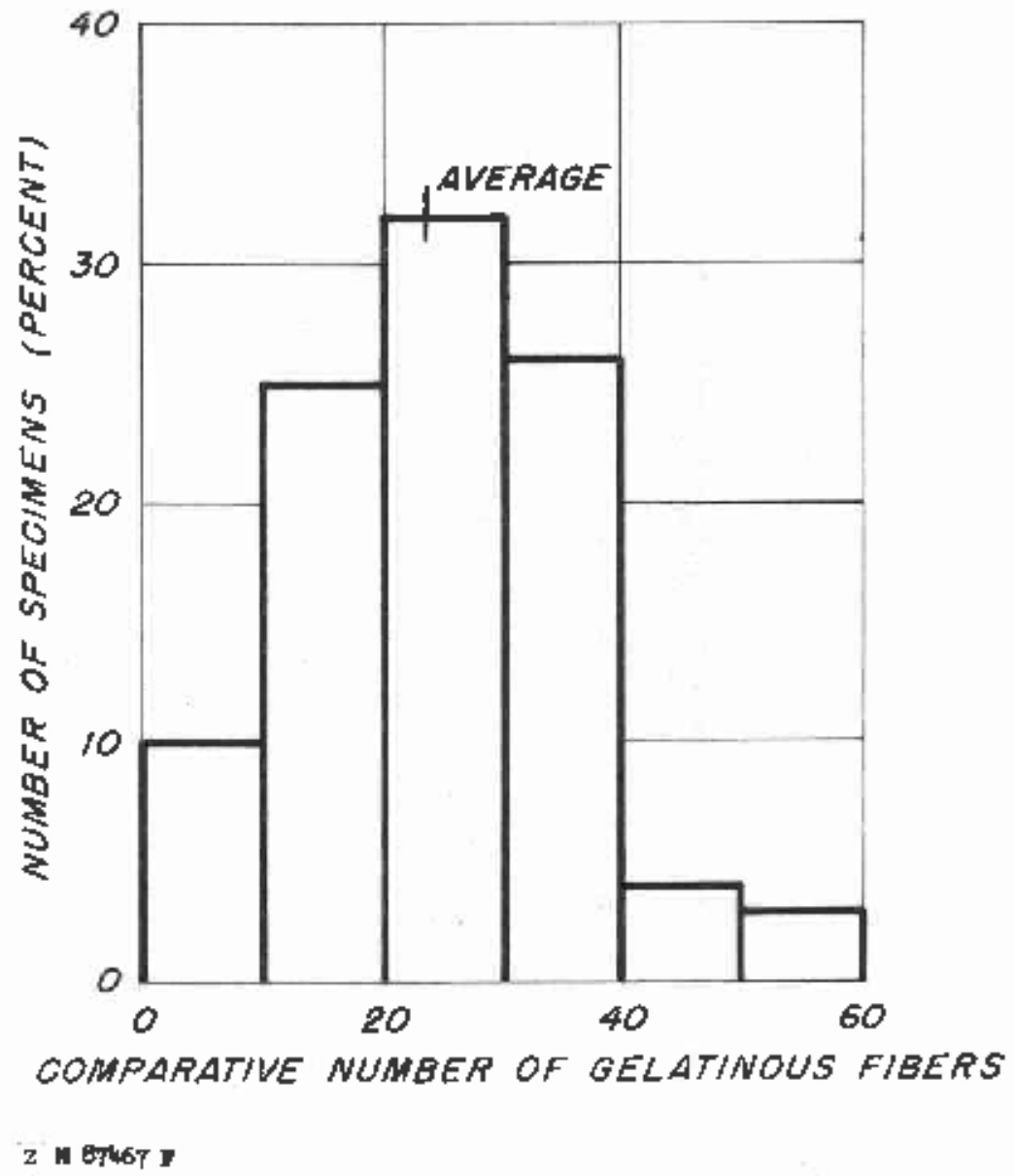



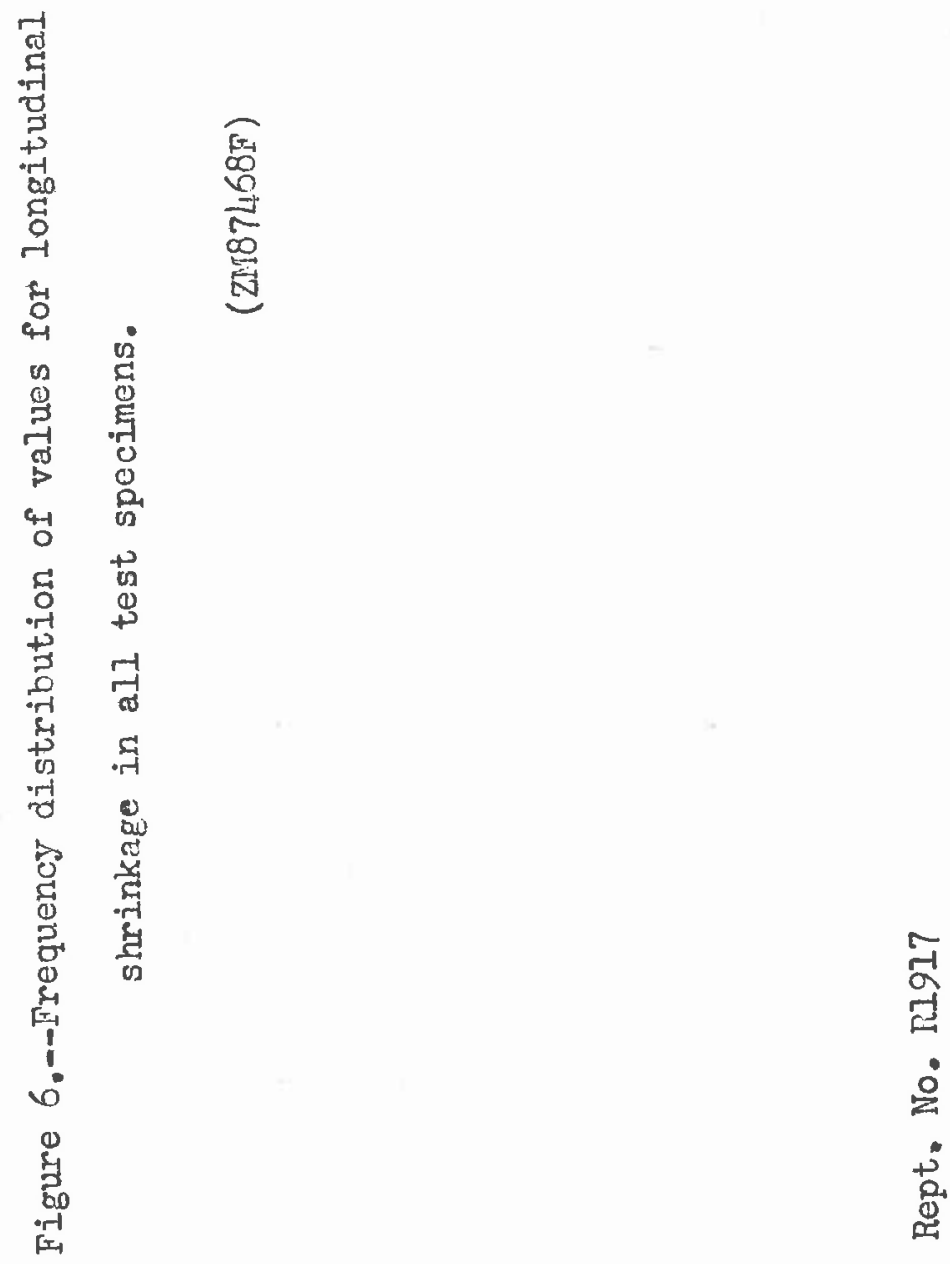


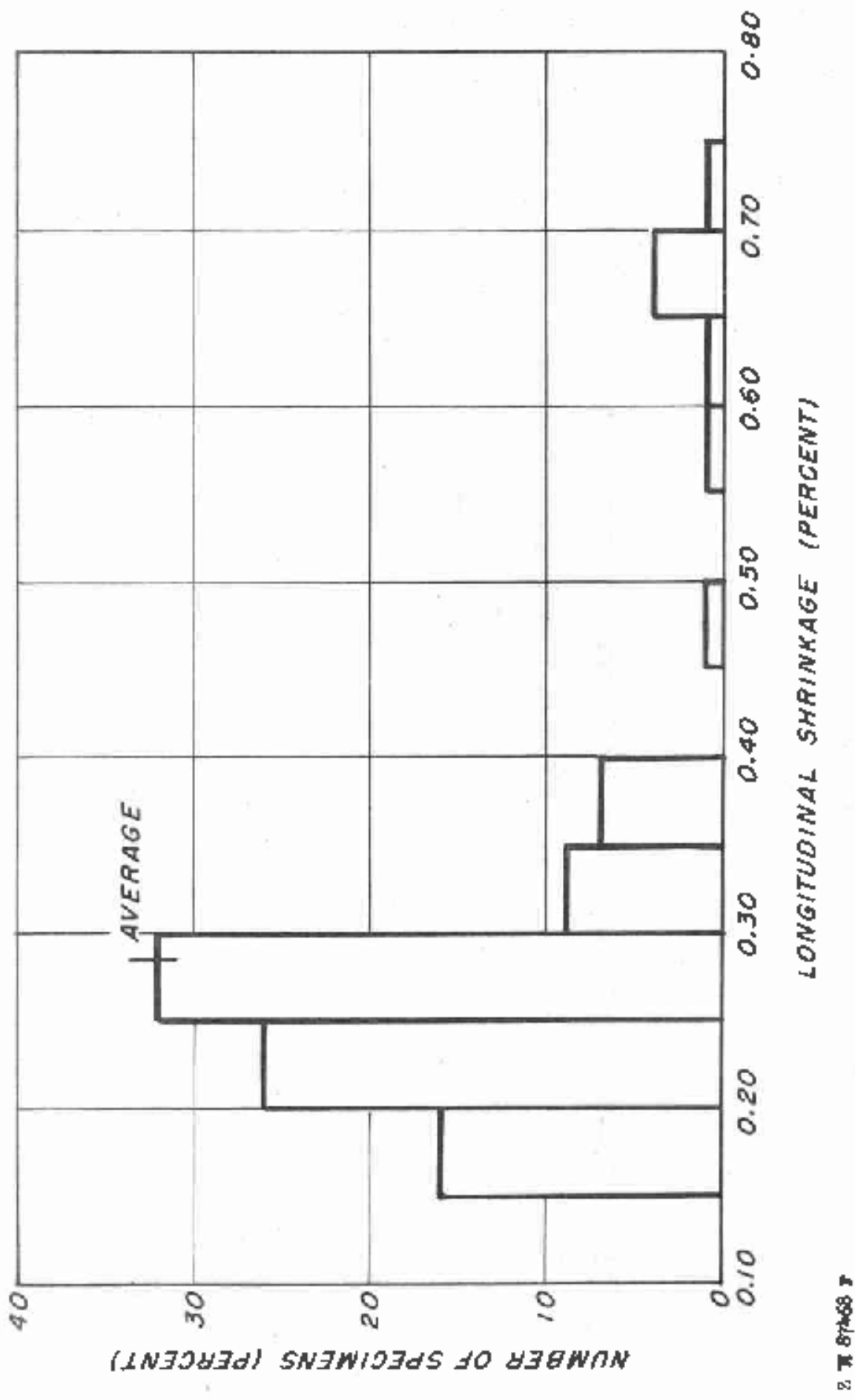




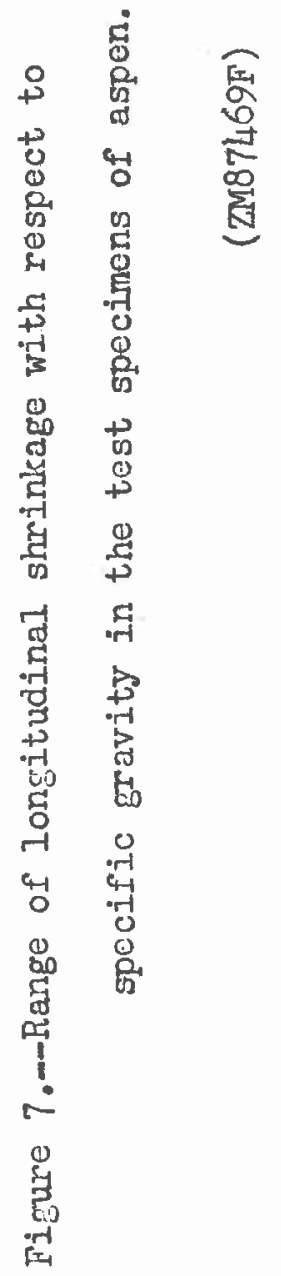

殅 


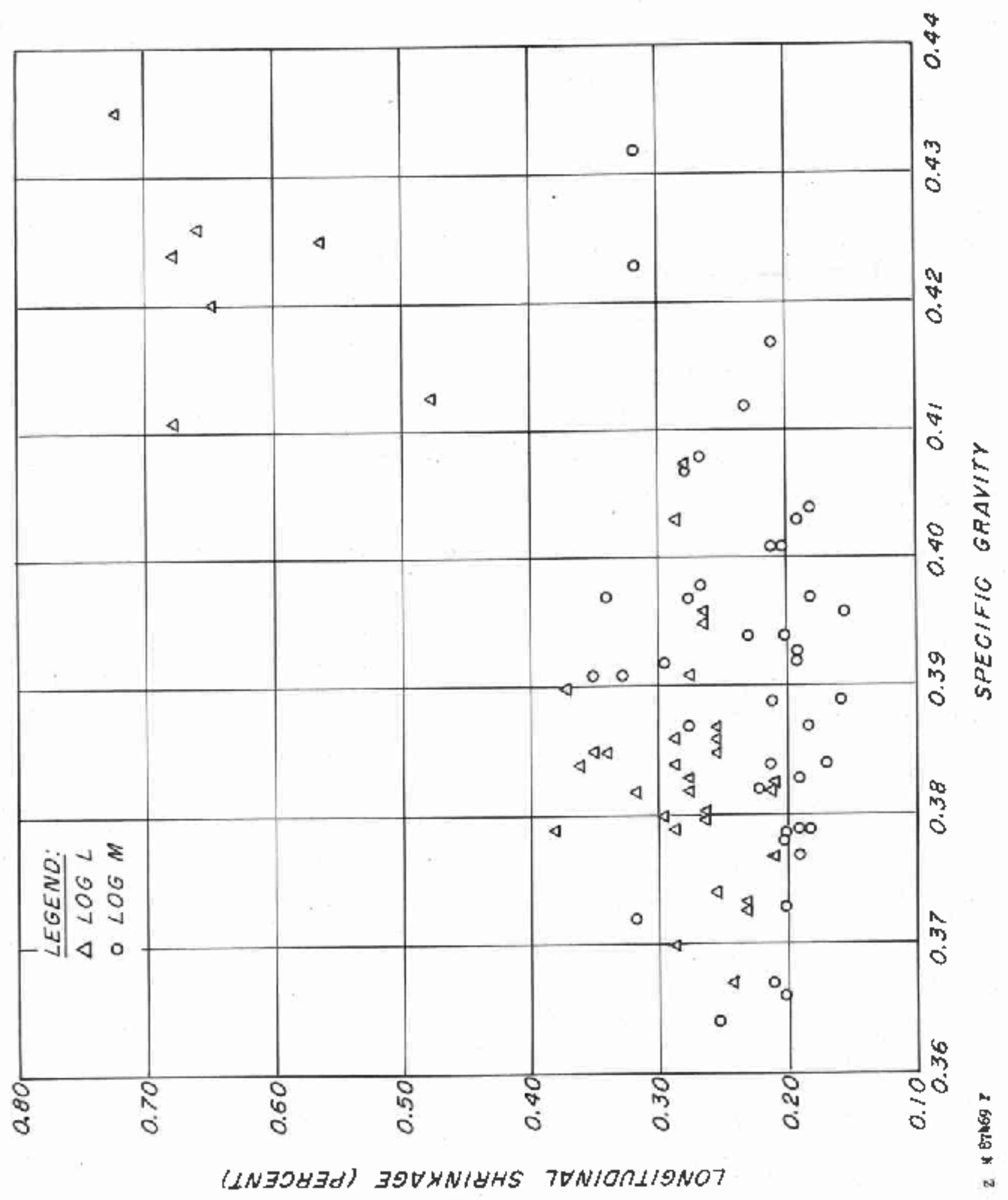


Fi ure 8.--Range of longitudinal shrinkage with respect to the comparative number of gelatinous fibers in the test specimens of aspen.

(ZM87470F)

Rept. No. RI917 


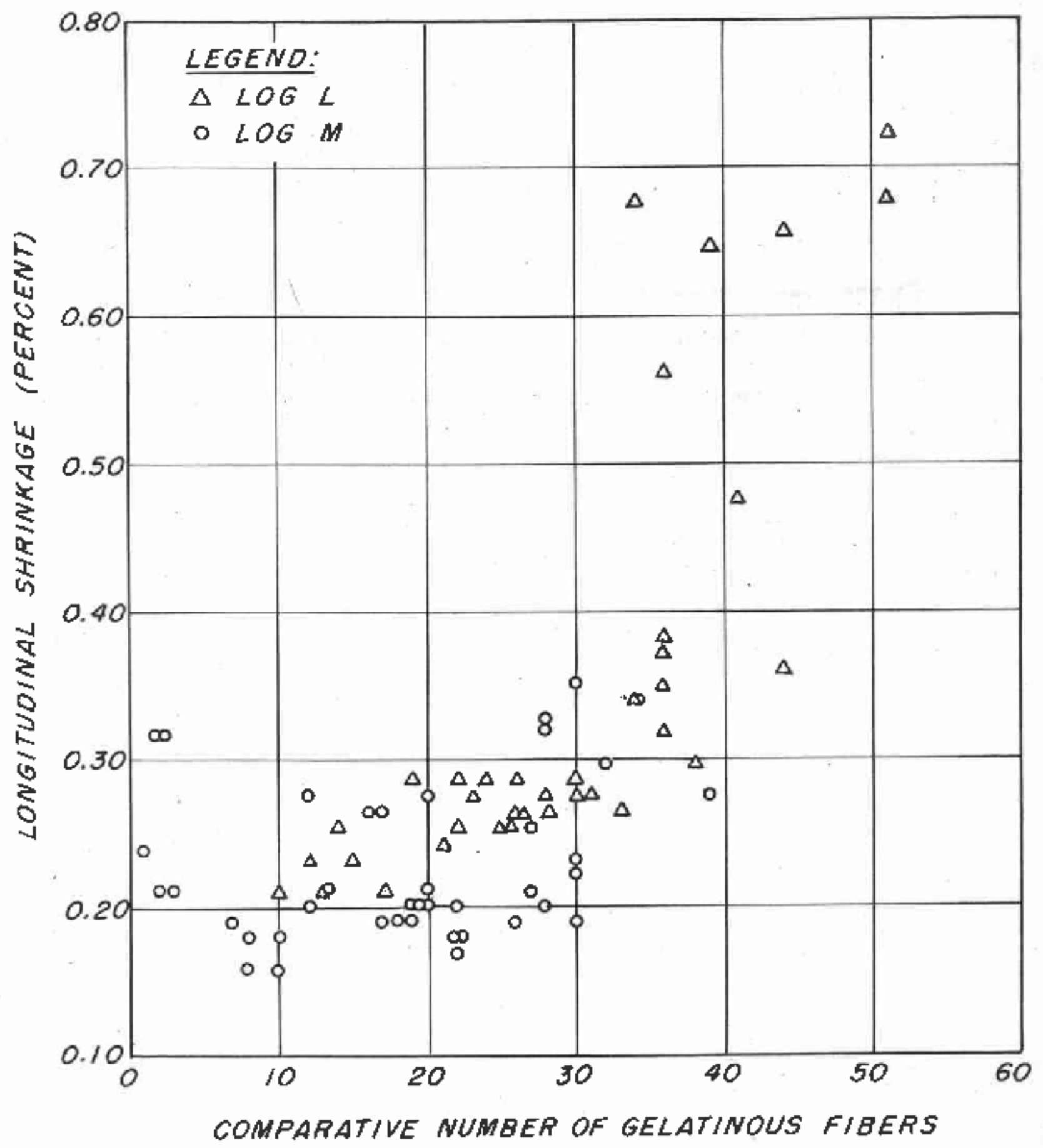

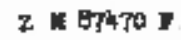


Figure 9,--A three-dimensional graph showing the combined effect of number of gelatinous fibers and specific gravity on longitudinal shrinkage in aspen.

$(\mathrm{ZT}: 87472 \mathrm{~F})$

Rept. No. R1917 


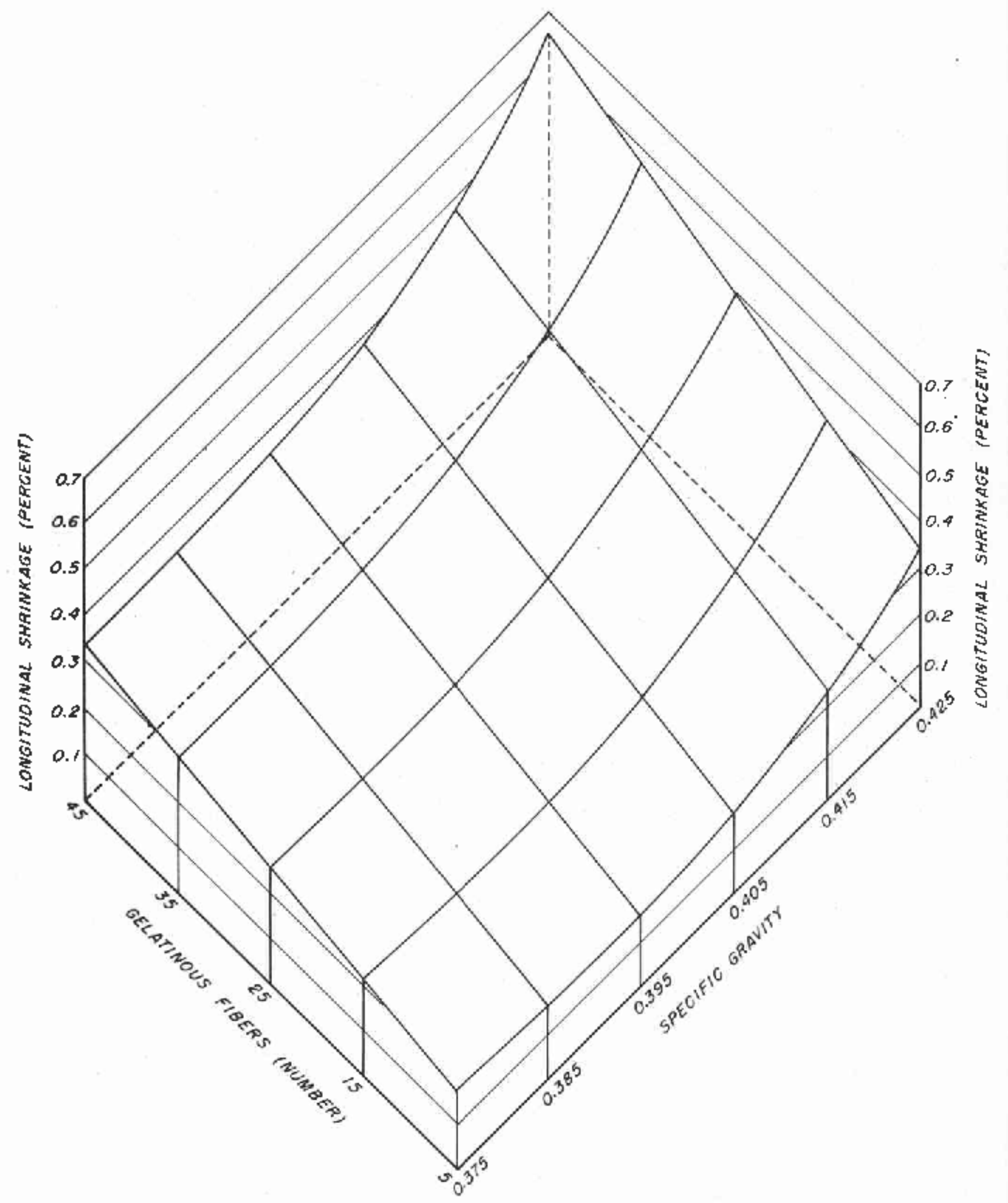

